See discussions, stats, and author profiles for this publication at: https://www.researchgate.net/publication/333067982

\title{
A dual-pathway model of knowledge exchange: linking human and psychosocial capital with prosocial knowledge effectiveness
}

Article in Journal of Knowledge Management · May 2019

DOI: 10.1108/JKM-08-2018-0504

\section{CITATIONS}

43

4 authors, including:

Sanjay Singh

National University of Ireland, Maynooth

88 PUBLICATIONS 2,885 CITATIONS

SEE PROFILE

Rabindra Kumar Pradhan

Indian Institute of Technology Kharagpur

99 PUBLICATIONS 1,010 CITATIONS

SEE PROFILE
Atri Sengupta

Indian Institute of Management Sambalpur

15 PUBLICATIONS 176 CITATIONS

SEE PROFILE

Some of the authors of this publication are also working on these related projects:

International Conference on Organization and Management (www.adu.ac.ae/icom2016), November 20-21, 2016 Abu Dhabi in association with Asia Academy of Management, Hong Kong View project

Antecedents and Consequences of Covid-19 Stress at Work View project 


\section{e emeraldinsight}

\section{Journal of Knowledge Management}

A dual-pathway model of knowledge exchange: linking human and psychosocial capital with prosocial knowledge effectiveness

Sanjay Kumar Singh, Shashank Mittal, Atri Sengupta, Rabindra Kumar Pradhan,

\section{Article information:}

To cite this document:

Sanjay Kumar Singh, Shashank Mittal, Atri Sengupta, Rabindra Kumar Pradhan, (2019) "A dual-pathway model of knowledge exchange: linking human and psychosocial capital with prosocial knowledge effectiveness", Journal of Knowledge Management, https://doi.org/10.1108/JKM-08-2018-0504

Permanent link to this document:

https://doi.org/10.1108/JKM-08-2018-0504

Downloaded on: 20 May 2019, At: 23:43 (PT)

References: this document contains references to 107 other documents.

To copy this document: permissions@emeraldinsight.com

The fulltext of this document has been downloaded 66 times since 2019*

\section{Users who downloaded this article also downloaded:}

(2019),"Employee perception of impact of knowledge management processes on public sector performance", Journal of Knowledge Management, Vol. 23 Iss 2 pp. 351-373 <a href="https://doi.org/10.1108/JKM-08-2017-0348">https:// doi.org/10.1108/JKM-08-2017-0348</a>

"Self-efficacy and workplace well-being: moderating role of sustainability practices", Benchmarking: An International Journal, Vol. 0 Iss 0 pp. - <a href="https://doi.org/10.1108/BIJ-07-2018-0219">https://doi.org/10.1108/BIJ-07-2018-0219</a>

Access to this document was granted through an Emerald subscription provided by emerald-srm:395687 []

\section{For Authors}

If you would like to write for this, or any other Emerald publication, then please use our Emerald for Authors service information about how to choose which publication to write for and submission guidelines are available for all. Please visit www. emeraldinsight. com/ authors for more information.

\section{About Emerald www.emeraldinsight.com}

Emerald is a global publisher linking research and practice to the benefit of society. The company manages a portfolio of more than 290 journals and over 2,350 books and book series volumes, as well as providing an extensive range of online products and additional customer resources and services.

Emerald is both COUNTER 4 and TRANSFER compliant. The organization is a partner of the Committee on Publication Ethics (COPE) and also works with Portico and the LOCKSS initiative for digital archive preservation.

*Related content and download information correct at time of download. 


\title{
A dual-pathway model of knowledge exchange: linking human and psychosocial capital with prosocial knowledge effectiveness
}

\author{
Sanjay Kumar Singh, Shashank Mittal, Atri Sengupta and Rabindra Kumar Pradhan
}

\begin{abstract}
Purpose - This study aims to examine a dual-pathway model that recognizes two distinct (formal and informal) but complementary mechanisms of knowledge exchanges - knowledge sharing and knowledge helping. It also investigates how team members use their limited human and psychosocial capital for prosocial knowledge effectiveness.
\end{abstract}

Design/methodology/approach - A survey-based approach was used to examine the hypotheses of the study. A moderated-mediation model was proposed and tested using bootstrap approach.

Findings - Knowledge sharing and knowledge helping were found to be the significant links through which human capital (capability) and psychosocial capital (motivation and efficacy) significantly predict prosocial knowledge effectiveness. Post hoc analysis suggests that human capital through knowledge sharing influences team learning, whereas the psychosocial capital through knowledge helping influences team leadership.

Originality/value - The present study found two distinct but complementary and yet necessary mechanisms of knowledge exchanges to be linked as the important outlay for the human and psychosocial capital to be effective in the prosocial knowledge behaviours.

Keywords Professional identity, Social identity theory, Capability, Knowledge exchange, Knowledge self-efficacy, Prosocial knowledge effectiveness

Paper type Research paper

\section{Introduction}

The knowledge management literature identifies knowledge exchange as a critical tool for enhancing collective learning (Acharya et al., 2018; Singh and Gupta, 2014; Levine and Prietula, 2012). This idea is embodied in the emergent research domain of knowledge governance (KG) (Ali et al., 2018). Foss et al. (2010, p.456) describes KG as "[...] mechanisms that can impact the courses of using[...].knowledge in chosen directions and toward chosen levels". Another definition describes KG as the "[...] combination of knowledge practices and their facilitating formal and informal mechanisms which allow moving the companies" (Pemsel et al., 2014, p. 9). we argue that KG emphasizes on organizational mechanisms - knowledge management processes, typologies and standards (Al Ahbabi et al., 2018; Loon, 2019), and incentives and control mechanisms - that direct behaviour of and connections between the people (Pemsel et al., 2016). Ali et al. (2018) suggest that control and incentives mechanisms which make sure successful execution of knowledge management processes.
Sanjay Kumar Singh is based at the College of Business, Abu Dhabi University, Abu Dhabi, United Arab Emirates. Shashank Mittal is based at the Rajagiri Business School, Cochin, Kerala, India.

Atri Sengupta is based at the Department of Organizational Behavior and Human Resources Management, Indian Institute of Management, Sambalpur, Sambalpur, India.

Rabindra Kumar Pradhan is based at the Department of Humanities and Social Sciences, Indian Institute of Technology, Kharagpur, India.

Received 14 August 2018 Revised 29 January 2019 Accepted 22 February 2019 
The emergence of knowledge exchange processes is influenced by motivational factors macro-level in the form of structural mechanisms and visionary mechanisms, and microlevel in the form of pragmatic mechanisms (Pemsel and Müller, 2012). Although KG literature advances the understanding of the motivational factors (Huang et al., 2013) in the form of incentives and control mechanisms (Quigley et al., 2007), extrinsic and intrinsic factors (Sedighi et al., 2016; Chou et al., 2014), and systems and practices (Ferraris et al., 2017), with two exceptions (Sedighi et al., 2016; Serenko and Bontis, 2016), there remains a dearth in understanding the knowledge exchange process that governs collective learning. In particular, there has been very little development in studying the nature and types of knowledge exchange process (Levine and Prietula, 2012; Wang and Noe, 2010; Humphrey et al., 2007). Even the two exceptions, i.e. the studies of Sedighi et al. (2016) and Serenko and Bontis (2016), do not focus on knowledge exchnage process, rather on the differentiation of knowledge exchanges based on motiavtional aspects. These leave aside the focus on knowledge exchange process and its formal and informal mechanisms as highlighted by Foss et al. (2010) in their review on KG. Foss et al. (2010) highlight that the literature on knowledge transfer assumes all types of exchange to be generic (Pemsel and Müller, 2012; Nicolini, 2011) in nature. They advocate future studies to differentiate and understand the formal and informal mechanisms of the knowledge exchange process operating at micro-level. This scant understanding of the knowledge exchange process (Pemsel et al., 2014) necessitates further investigation of how employees engage in collective behaviour (Acharya et al., 2018; Al Ahbabi et al., 2017; Foss et al., 2010).

The present study aims to shift the primary focus from motivational factors to collective learning through the lens of knowledge exchange; specifically, the nature of social exchanges and the process that governs the individuals involved in knowledge exchange. This shift will enable us not only to better understand the process, but also will provide a better way to design and manage it, as suggested by Pemsel et al. (2016) and Foss et al. (2010).

The social feature of management of knowledge, in the form of interactions and relations between colleagues, is a critical element of system to manage knowledge (Duffield and Whitty, 2016) and an emergent development in the KG literature (Holzmann, 2013). Deriving from the relational architecture of work design (Grant, 2007) and social exchange theory, the present study proposes two different types of social exchange - knowledge sharing (formal mechanism) and knowledge helping (informal mechanism). Therefore, we posit that social exchange theory helps develop understanding of the knowledge exchange practices at workplace (Liu et al., 2012; Hall et al., 2010). It has varying effects on how individuals get involved in the collective learning by channelizing their limited human and psychosocial capital. As noted, till now, the knowledge management research has almost unilaterally considered knowledge exchanges as a generic form of social exchange having unidimensional properties (Serenko and Bontis, 2016; Wang and Noe, 2010).

The present study proposes that knowledge exchanges are a bundle of activities or tasks which govern social exchange (Al Ahbabi et al., 2018; AlShaima et al., 2016; Cropanzano and Mitchell, 2005). Further, the knowledge management literature gains little benefit from work design and social exchange literatures that explain how organizations, managers, and individuals manage knowledge exchange activities (Al Ahbabi et al., 2017; Foss et al., 2015) through relational work design (Grant, 2007; Humphrey et al., 2007). Hence, the present study proposes two alternative but complementary mechanisms in the form of reciprocal/formal (operationalized as knowledge sharing) and altruistic/informal (operationalized as knowledge helping) knowledge exchanges through which an individual uses human and psychosocial capital to participate in collective learning. These mechanisms have one similarity that they can both be governed and managed by managers. However, the design elements are different for both; reciprocity or formal follows an incentive and control structure (Spitzmuller and Van Dyne, 2013), whereas altruistic or 
informal follows relational work design (Grant, 2007). The former design is less sustainable and needs alterations from time to time and may even form bottlenecks once the extrinsic factors are removed (Laursen and Foss, 2014; Osterloh and Frey, 2000). But the latter can bring long-term results, as once the design is in place, individuals are automatically motivated to participate (Foss et al., 2015; Grant, 2007). Therefore, the right combination may provide an optimum mix of short-term and long-term design elements for the organization/manager.

Our study make three contributions to advance literature on knowledge exchanges and collective learning. First, we developed and tested a dual-pathway model of formal and informal knowledge exchanges - knowledge sharing and knowledge helping - that governs prosocial knowledge effectiveness in teams. Second, our study explored on how human and psychosocial capital together influence prosocial knowledge effectiveness in teams through interlinking processes. Finally, this study suggests implications for the design of the optimum mix of relational work and extrinsic control mechanisms.

We arrange our paper as follows. Section 2 presents literature review followed by hypotheses development and methods in Sections 3 and 4, respectively. Sections 5 and 6 present results and discussion, respectively.

\section{Literature review}

\subsection{Antecedents of prosocial knowledge effectiveness}

The roles of extrinsic and intrinsic motivational factors are distinguished in KG literature. Studies highlighting extrinsic motivational factors (Chou et al., 2014; Lin, 2007) focus mostly on reciprocity aspects, as designing incentive structure and control mechanisms are common in organizations (Nicolini, 2011; Grant, 2008) for facilitating collective learning. However, despite their usefulness, there exist limitations in promoting these factors. The previous literature reveals that with the alterations of incentives and control structures, individuals are less inclined to contribute to collective learning (Laursen and Foss, 2014), because the effects of extrinsic factors are mostly temporary in nature. When these factors are withdrawn, the motivation level of an individual falls below the initial level (Laursen and Foss, 2014; Osterloh and Frey, 2000).

Furthermore, at an interpersonal level, the cost-benefit analysis leads to mistrust among the members, which results in a severe bottleneck in collective learning (Spitzmuller and Van Dyne, 2013). This necessitates examining the role of intrinsic factors in collective learning. However, the focus of the extant literature has been entirely on dispositional factors (Grant, 2007), which are difficult for an employee to change, therefore, having limited applications in practice (Grant, 2012). This paucity in practical implications (Laursen and Foss, 2014; Grant, 2008) warrants an understanding about "who, when and how" of individual's participation in collective learning; more specifically, when and how employees use their human and psychosocial capital to participate in social exchanges and exhibit team learning and team leadership.

\subsection{Human and psychosocial capital in prosocial knowledge effectiveness}

Human and psychosocial capital play crucial roles in knowledge exchange. Human capital is referred as the sum of knowledge, skills and abilities (KSAs) of an individual. Table I shows the operationalizations and definitions of the constructs. Grant and Ashford (2008) highlight that the process dynamics of KSAs for prosocial knowledge effectiveness may be distinct from the dynamics of KSAs for self-oriented effectiveness, which mostly involves task-related self-learning (Schmidt and Hunter, 2004; Hunter and Schmidt, 1996) in the process. 
Table I Construct operationalization and definitions

\begin{tabular}{|c|c|c|}
\hline Construct & Operationalization & Definition \\
\hline Human capital & KSAS & Knowledge, skills and abilities \\
\hline $\begin{array}{l}\text { Psychosocial capital } \\
\text { (Specific efficacy, } \\
\text { motivation) }\end{array}$ & $\begin{array}{l}\text { Knowledge self-efficacy } \\
\text { (KSE), } \\
\text { Professional-role- } \\
\text { identity(PRI) }\end{array}$ & $\begin{array}{l}\text { Knowledge self-efficacy is an individual's belief about the useful contribution which } \\
\text { can be done through sharing one's KSAs to other members (Kankanhalli et al., } \\
\text { 2005); this specific self-efficacy covers two things - confidence in one's expertise } \\
\text { and usefulness of that expertise for others (Kankanhalli et al., 2005) } \\
\text { Professional role identity is defined as motivations arising out of internalization of } \\
\text { professional values, roles and identities }\end{array}$ \\
\hline Knowledge exchange & $\begin{array}{l}\text { Knowledge sharing } \\
\text { (KS) } \\
\text { Knowledge helping } \\
\text { (KH) }\end{array}$ & $\begin{array}{l}\text { Knowledge sharing refers to sharing of one's knowledge in teams. This is usually } \\
\text { routine, in-role (especially for explicit knowledge), and reactive in nature, that usually } \\
\text { happens when asked for (Huang et al., 2014) } \\
\text { Knowledge helping refers to team directed helping behaviours and is concerned } \\
\text { mainly with proactive aspects of helping (Spitzmuller and Van Dyne, 2013) - } \\
\text { professional development and problem mitigation - for team members through the } \\
\text { use of knowledge (Mittal et al., 2018; Sedighi et al., 2016) }\end{array}$ \\
\hline $\begin{array}{l}\text { Prosocial knowledge } \\
\text { effectiveness (PKE) }\end{array}$ & $\begin{array}{l}\text { Team learning and } \\
\text { Team leadership }\end{array}$ & $\begin{array}{l}\text { Team learning is the collective learning directed towards team. 'Team Leadership' is } \\
\text { defined as the responsibility assumed by a team member, who is not the supervisor } \\
\text { or formal team leader/manager, of satisfying team's needs in the service of } \\
\text { enhancing team effectiveness (Morgeson et al., 2010) }\end{array}$ \\
\hline
\end{tabular}

Undoubtedly, a lack of KSAs may lead employees to put a restraint in exchanging knowledge (Bunderson and Reagans, 2011) or proactively helping others (Grant and Ashford, 2008). There may also be the circumstances in which, even after having an adequate KSAs, employees may not engage in knowledge exchanges because of the restrictions imposed by two important aspects of psychosocial capital - motivation and efficacy (Bunderson and Reagans, 2011; Grant and Ashford, 2008). Psychosocial capital (motivation and efficacy) is the distal antecedent of various parameters of effectiveness, whereas human capital (KSAs) is the proximal antecedent of effectiveness (Van Iddekinge et al., 2009). Human (KSAs) and psychosocial capital (motivation and efficacy) are individual characterstics that form differences in individual capital leading to differencials in effectiveness. Motivation is operationalized in terms of professional role identity, which arises out of internalization of professional values, roles, and identities. Knowledge self-efficacy denotes to a person's belief about the useful contribution to be made through sharing one's knowledge with other members. It consists of confidence in one's expertise and usefulness of that expertise for others (Kankanhalli et al., 2005).

There has been a repeated call to understand the role of human and psychosocial capital in proactive and prosocial behaviour (Grant and Ashford, 2008; Fay and Frese, 2001). Surprisingly, scant attention has been paid to human and psychosocial capital in collective learning (Grant, 2012; Grant and Ashford, 2008). Earlier research mostly examine the use of human and psychosocial capital for self-oriented benefits, paying little attention to identifying their role in others-oriented benefits (Parker et al., 2010; Grant and Ashford, 2008). Drawing upon the work design and the social exchange theory, we posit that when human and psychosocial capital are used in social exchanges, it makes self and others more significant, thus shifting the frame of social exchanges from the cost to the benefit orientation (Grant, 2008; Humphrey et al., 2007; Perlow and Weeks, 2002). When individuals perceive that more meaningful and significant contribution can be made through their involvements in task-related social exchanges (Grant, 2008; Humphrey et al., 2007), their involvement in collective learning increases. This is because one can create a larger impact in the lives of others by channelizing their human and psychosocial capital in holistic and significant social exchanges (Humphrey et al., 2007). 


\subsection{Knowledge exchanges in prosocial knowledge effectiveness}

The present study considers knowledge helping as a kind of social exchange that provides complete and significant meaning for self and others (Sedighi et al., 2016). Therefore, knowledge helping and knowledge sharing complementarily link employees' human and psychosocial capital with their collective learning process. Knowledge exchanges may happen with voluntary and involuntary participation of knowledge holders (AIShaima et al., 2016; Sedighi et al., 2016). A common form of knowledge exchange as identified by earlier research is knowledge sharing which captures the involuntary aspects of need-based exchanges - a reactive form (Al Ahbabi et al., 2018; AlShaima et al., 2016; Huang et al., 2014). Knowledge sharing, being egoistic, usually occurs in bits and pieces (Perlow and Weeks, 2002). The person involved in knowledge sharing has little idea about its true nature and significance, as little is known about its application at the receiver's end (Humphrey et al., 2007). Therefore, sometimes instead of perceiving greater good, persons assess the cost of sharing personal resources in the form of human and psychosocial capital (Perlow and Weeks, 2002). Unfortunately, the knowledge exchange literature is silent about helping or proactive (informal) forms of exchange (Mittal et al., 2018; AlShaima et al., 2016). In line with earlier scholars (Mittal et al., 2018; Sedighi et al., 2016), we argue that both forms of exchanges possess distinctive characteristics. Therefore, the present study defines knowledge exchanges in terms of knowledge sharing (reactive) and knowledge helping (proactive). Table II describes differences and commonalities in knowledge sharing and knowledge helping.

The frame of helping changes from cost structure to benefit structure when helping is associated with the development of self and others (Spitzmuller and Van Dyne, 2013; Perlow and Weeks, 2002). By knowledge helping in the form of professional development and problem mitigation, employees engage in interactional activities leading to a sense of higher significance and greater impact on self and others (Spitzmuller and Van Dyne, 2013). Previous literature states that development and loss prevention activities (e.g. problem mitigation) have a greater impact on self and others (Grant, 2007). Moreover, they provide an opportunity for more prolonged/continuous and close contact with the beneficiaries (Grant, 2007). Therefore, the helper closely witnesses and experiences the benefits of knowledge helping (Spitzmuller and Van Dyne, 2013) that play an important role in interactions.

Considering the above-mentioned arguments, we propose a model (Figure 1) which draws its root from social identity theory, self-efficacy theory, and social exchange theory. The following section develops hypotheses using the underlined theoretical lenses.

Table II Differences and commonalities in knowledge sharing and knowledge helping

Knowledge sharing (formal)

Motive

Design

Duration Impact on self and others

Nature of interaction

Nature of tasks or knowledge

Commonality
Reciprocity; usually asked for; reactive Cost-benefit structures; control mechanisms and incentive structure; design can be altered easily Short-term; benefits are less sustainable Limited as interactions happen in bits and pieces so limited awareness of the significance or impact on others Interactions in bits and pieces; constrained opportunity to clearly see and directly experience the larger picture of self and others benefit Routine; mainly day-to-day; more applicable in codified knowledge Both can be designed
Knowledge helping (informal)

Altruistic; self-driven; proactive

Identifying ways through which interaction becomes significant for self and others; facilitation of changing frame from cost to benefit structure; relationship-orientation; limited options for alteration Short and long term; benefits are more sustainable Provides more opportunity to see larger picture of higher significance and impact for self and others benefit

More continuity of interactions; greater opportunity to clearly see and directly experience the larger picture of higher significance for self and others benefit

Developmental; problem focussed; more applicable in implicit knowledge 


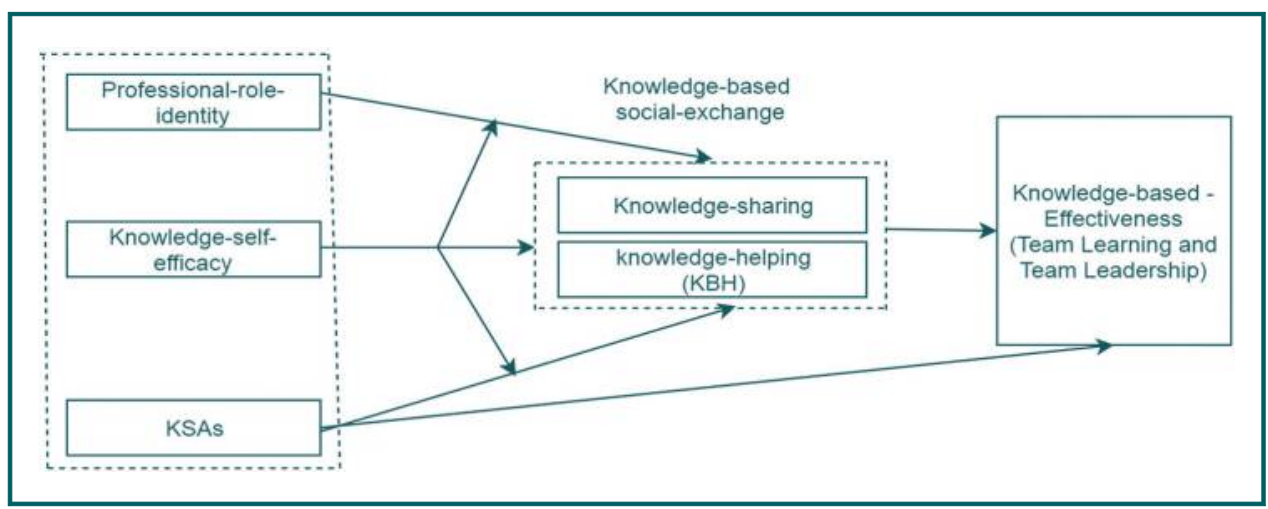

\section{Hypothesis development}

\subsection{Professional role identity, knowledge self-efficacy and knowledge exchange}

Professional role identity is refers to relatively steady and enduring internalization of values, roles, qualities, and experiences which form part of the self-concept in a professional role (Ibarra, 1999; Schein and Schein, 1978). Professionals are characterized by actions and intentions. It can be said that in professional and knowledge-based work, employees have high regard for KSAs because of their significance in the case of work. Hence, they form an integral aspect of one's professional role identity, which influences employee behaviour due to its saliency in professional organizations.

An individual who believes in professionalism fulfils his/her professional role by contributing towards professional knowledge and community. He/she looks for an opportunity to showcase and verify the same socially through other people (Swann, 1990). This enactment of identity happens based on the social cues available from the environment and importance attached to the specific identity (Swann and Buhrmester, 2012). The enactment satisfies the need for self-expression, self-verification, and contribution (Ashforth and Johnson, 2001). KSAs are indispensable tools for the fulfilment of these needs which, in fact, provide the reason and valence associated with KSAs in the service of fulfilling the professional role. Hence, individual who places high regard for professional role identity, his/her various needs (Ashforth and Johnson, 2001) are satisfied by sharing and helping professional and fellow team members. Knowledge sharing and knowledge helping act as the channel for an individual to express and fulfil personal self through benefitting others and satisfy the social self of expertise identity through self-verification (North and Swann, 2009), self-expression and contribution.

A person's general self-efficacy is a stable, trait-like belief in his/her competence (Singh et al., 2019; Chen et al., 2001; Bandura, 1997). General self-efficacy is distinct from taskspecific self-efficacy, which is a belief about one's ability to perform a defined task. It has been extensively studied and its link to individual performance has been consistently established (Judge et al., 2007; Chen et al., 2001). General self-efficacy also affects the attributions people make about their performances (Bandura, 1997). For instance, people with high general self-efficacy are more likely to attribute their success to personal ability, while attributing failures to factors outside their control, such as job conditions. Previous studies (Kankanhalli et al., 2005) reveal that person's specific self-efficacy in the domain of knowledge application has a positive effect on employees' contributions to knowledge management efforts. 
Conversely, people who place greater importance on professional role identity, but are low in knowledge self-efficacy, may have the same desire to verify their identities by knowledge sharing and knowledge helping. However, the lack of confidence in the ability to effectively apply professional KSAs in solving job-related problems (Constant et al., 1996) or improving work efficacy (Baer and Oldham, 2006) may deter them. They may not have enough confidence that others will perceive them as professionals. People with a strong professional role identity and low knowledge self-efficacy may doubt their abilities to effectively communicate or assert their professional roles. Their efforts to share knowledge and help others often create negative perceptions amongst team members about their professional knowledge. Hence, they lack confidence in creating positive perceptions and desirable impact on others (DeRue and Morgeson, 2007).

Hofmann et al. (2009) reveal that people seek help from professional experts only in the context of complex and ambiguous situations, leading to individuals' engagement in knowledge helping and knowledge sharing. From the above, it is evident that professional role identity is very important for helping, but one's belief in her/his knowledge plays a crucial role for both knowledge sharing and knowledge helping. An individual having inadequate KSAs does not participate in knowledge helping and knowledge sharing.

As mentioned above, KSAs play vital role in both knowledge helping and knowledge sharing. Individuals with confidence in their KSAs are willing to help others, whereas individuals lacking confidence prefer to withdraw from helping, even if they have high professional role identity. Knowledge self-efficacy adequately captures the degree of confidence one has in his/her KSAs. Knowledge self-efficacy is an individual's belief in the useful contribution he/she makes through sharing his/her KSAs with other members (Kankanhalli et al., 2005). Therefore, person with high level of professional role identity will have a high propensity to help, but having low knowledge self-efficacy will deter him/her to do so because of the doubt on the relevance of his/her expertise for others. On the other hand, an individual having a low level of professional role identity and a high level of knowledge self-efficacy will not impact his/her willingness to help. Hence, we propose that:

H1a. Interaction between professional-role-identity and knowledge self-efficacy is positively related to knowledge sharing such that people with strong professionalrole-identity are more likely to share knowledge when knowledge self-efficacy is high but less likely to share when knowledge self-efficacy is low.

H1b. Interaction between professional-role-identity and knowledge self-efficacy is positively related to knowledge helping, such that people with strong professional identity are more likely to help when knowledge self-efficacy is high but less likely to help when knowledge self-efficacy is low.

\subsection{Knowledge, skills and abilities, knowledge exchange and prosocial knowledge effectiveness}

One must have the requisite capabilities for performing any kind of work. Individual differences and contextual factors are crucial in explaining the differences in individual performances (Schmidt and Hunter, 2004). The situational view dominates in the previous literature; however, the psychology of individual differences has started gaining momentum (Lubinski, 2000). Therefore, we suggest to emphasize personality and other domainspecific traits, skills, experience, gender, values, general intelligence, interests and domainspecific abilities and aptitudes as the basis of individual and group differences.

A similar trend is observed in the case of various types of proactive and prosocial behaviours influencing individual performance. One needs to possess job-relevant KSAs and understanding of job related requirements of fellow team members to render help (Grant and Ashford, 2008). Because less capable individuals can neither help self nor others in their professional development. Such individuals find difficulty in identifying and 
understanding the work requirement of self and other team members and possible ways to help.

Some other studies highlight linkages between individual capabilities and various forms of social exchanges. For example, Fay and Frese (2001) find that a high level of KSAs is associated with a greater level of personal initiative. Another series of studies in the psychology of individual differences draw our attention towards the significance of mental ability, knowledge, proactive learning behaviour and personality in performance (Schmidt and Hunter, 2004; Hunter and Schmidt, 1996). The role of knowledge and skills is particularly relevant to various proactive behaviours in ambiguous and fast changing environments that generates subjective and ambiguous circumstances for the employees. The present research takes an amalgam of KSAs together as individual capabilities to influence social exchange and aspects of effectiveness, especially in the knowledge-worker context. Based on prior literature (Blader and Chen, 2012; Hofmann et al., 2009; Faraj and Sproull, 2000), KSAs are operationalized as job experience, self-reported proficiency in the work domain and formal position in organizational hierarchy respectively. All the three dimensions are measured on a five-point rating scale and used to form a single overall score of capability aspect of KSAs.

Work experience reflects that an individual's tacit knowledge, or non-explicit knowledge, is achieved by participating in the work (Reuber and Fischer, 1994; Becker, 1964). Hofmann et al. (2009) consider job experience as help providers' attributes, which are responsible for help-seekers' perceptions of help-providers' expertise defined as a person's skill, competence, expertise, and knowledge. Prior research shows that work experience functions as a resource that affects career growth (Westhead, 1995; Bird, 1988). Helpseekers consider the formal position of help-providers as another attribute responsible for help seekers' accessibility perception (Hofmann et al., 2009). The literature on power and politics states that individuals who occupy higher positions in the hierarchy of the organizations are considered more influential as they exercise power through their access to, and control over, valuable resources (Blader and Chen, 2012).

A belief that one has a high level of confidence in one's ability, and can successfully pursue a specific domain, is likely to be important for proactive and prosocial behaviours. This is because being prosocial and proactive involves perceived cost of action (which can be managed through capabilities), and the risk of becoming exposed and vulnerable to others by displaying one's knowledge during knowledge exchange (a risk to the individual's ego and perceived image which requires self-efficacy). Prior researchers have indicated that specific efficacy perceptions are important in the prediction of the relevant target of impact (Ohly and Fritz, 2007; Freese et al., 2006; Parker et al., 2006). In line with this, knowledge self-efficacy adequately captures the degree of confidence one has in one's KSAs. Knowledge self-efficacy is an individual's belief about the useful contribution he/she can make through sharing his/her KSAs with other members (Kankanhalli et al., 2005). Therefore, knowledge self-efficacy is likely to provide boundary condition to the role of capabilities in knowledge exchange. Individuals having high capabilities would be able to manage the cost associated with indulging in knowledge-based exchanges. However, an individual who is low in self-efficacy may shy away from knowledge-based exchanges because of the low confidence to carry and sustain such exchanges. Therefore, we hypothesize that:

H2a. Interaction between KSAs and knowledge self-efficacy is positively related to knowledge sharing such that people with strong KSAs will be more likely to share knowledge when knowledge self-efficacy is high but less likely to share when knowledge self-efficacy is low.

H2b. Interaction between KSAs and knowledge self-efficacy is positively related to knowledge helping such that people with strong KSAs will be more likely to help, when knowledge self-efficacy is high but less likely to help when knowledge selfefficacy is low. 


\subsection{Knowledge exchange and prosocial knowledge effectiveness}

Contemporary leadership studies emphasize the role of leadership in teams (Morgeson et al., 2010). The leadership functions are not confined to formal leadership but include informal leadership at the team level that includes various leadership functions exhibited by team members. Team leadership means members acting as leader fulfilling various requirements of the team (DeRue and Ashford, 2010). A team leader acts as a facilitator for the team members to perform important functions as a whole (Morgeson et al., 2010).

In present study, we examine team effectiveness in terms of contribution to team learning and team leadership. Today, organizations consider knowledge as a means of competitive advantage. Thus, organizations place high value on individuals with high professional expertise. Those individuals often enjoy power and influence in the organization. Expertise is recognized, revered, coveted and very influential in nature. Teams involved in knowledge-based complex tasks, such as nursing, engineering and information technology (IT), often face complex and ambiguous situations due to the conflicting demands of their jobs (Hofmann et al., 2009). As these jobs are mainly knowledge-based, individuals who are relatively less experienced face problems of know-when and know-how in implementing their tasks.

Learning contribution in the team is a part of overall development efforts which is similar to informal mentoring (Kammeyer-Mueller and Judge, 2008) that not only comprises helping the team members, directly and indirectly, with know-what and know-how of the task at hand but also helping them develop for more stimulating tasks in future. Individual who exhibit more knowledge sharing and helping behaviours affects her/his colleagues' learning and development in the team situation. Such individuals will exhibit trustworthiness and reliability (Morgeson et al., 2010) in knowledge sharing that would be missing otherwise.

For knowledge workers, facing complex and ambiguous situations is part of their routine work. They look for support and assistance from someone who can render help through sharing task-specific know-how and know-what to handle such situations. Some individuals handle and fulfil such needs of their team members by advising and assisting them and become influential in the team because knowledge is power. These individuals become provider and giver by sharing their part of knowledge that is essential for the survival and growth of the team (Morgeson et al., 2010).

These individuals connect at large with the teams and solve their problems. They act as informal mentors to relatively inexperienced individuals whom they provide support and development for their jobs. Therefore, where knowledge has consequential effects on task execution and completion, individuals helping others through knowledge and know-how are able to exert considerable influence on team members and act as team leaders. They fulfil the knowledge demands of their team members. Therefore, we predict that:

H3. KSAs are positively related to prosocial knowledge effectiveness through (a) knowledge sharing and (b) knowledge helping.

H4. Knowledge self-efficacy is positively related to prosocial knowledge effectiveness through (a) knowledge sharing and (b) knowledge helping.

H5. Professional role identity is positively related to prosocial knowledge effectiveness through (a) knowledge sharing and (b) knowledge helping.

H6. Knowledge self-efficacy moderates the indirect relationship between professional role identity and prosocial knowledge effectiveness through (a) knowledge sharing and (b) knowledge helping.

H7. Knowledge self-efficacy moderates the indirect relationship between KSAs and prosocial knowledge effectiveness through (a) knowledge sharing and (b) knowledge helping. 


\section{Method}

\subsection{Research setting and sample details}

Considering the focal point of the study, knowledge-intensive organizations with flat structure are more appropriate to be investigated. Therefore, we chose medium and largesized IT and technology-based organizations with flat reporting structures in their teams. As the present study investigates informal knowledge exchange process and team leadership, teams with flat reporting structures are more suitable to have clear exposition of informal mechanisms (Kirsch, 1996; Ouchi, 1980). Initially, we contacted 29 firms listed as mediumand large-scale IT and technology organizations from one of the northern region states of India, but only 16 fulfilled our criteria of knowledge-intensive organizations and flat reporting structures in teams. Out of 16 organizations, only 9 agreed to participate in our study, indicating a sampling rate of more than 56 percent, which was way higher than the acceptable level of satisfactory rate (Malhotra and Grover, 1998). Each of these organizations had more than 300 employees working in India and a turnover of more than US\$10m.

Based on the past literature on knowledge management (Garicano and Wu, 2012; Osterloh and Frey, 2000), the project-based and research and development (R\&D) teams in the technology or IT domain from those nine organizations were chosen for the study. The teams were shortlisted based on the inputs of the management keeping their suitability and availability in mind. Teams playing the roles of support functions for core project and R\&D teams were not considered for the study. Some of the project and R\&D teams could not be considered because of the unavailability of team supervisor or due to pressure of deadlines; thus, 21 such teams did not participate.

In total, 51 teams agreed to participate from nine organizations. These were knowledge-based teams and highly dependent on the knowledge resource to carry out their tasks successfully. Employees were primarily "knowledge-based workers" and often engaged in knowledge-based social exchanges. They were members of knowledge-based production teams, placing a lot of emphasis on their professional roles and expertise (Wu, 2015; Osterloh and Frey, 2000). Table III presents demographic details of the respondents in the study. We compared the demographic details of the participating teams with the 21 teams left out and found insignificant difference between the two groups. As such, we conducted analysis of variance (ANOVA) of the differences in means for the two groups for the demographic variables. The hypotheses of differences in the means were rejected (F-values $<1.9$ ). That suggests that non-response bias did not affect the data of this study.

\subsection{Procedures}

We considered recommendations of Podsakoff et al. (2003) to deal with common method biases. We used different sources to collect the data on independent and dependent variables. The source of data on the dependent variable was the supervisor and the source

\section{Table III Demographic details of the participants}

\begin{tabular}{l} 
Demographic indicator \\
\hline Total work experience in the field \\
Tenure within current organization \\
Tenure within current team \\
Age \\
Gender
\end{tabular}

$\begin{array}{cc}9 \text { years } & 4.4 \text { years } \\ 4 \text { years } & 1.6 \text { years } \\ 1.7 \text { years } & 0.8 \text { years } \\ 38 & 9.6 \text { years } \\ \text { male, } 26 \% \text { female } & \text { Not applicable }\end{array}$


for the independent variable was employees. We administered survey questionnaire to the respondents in a face-to-face situation. It is important to note that we explained the purpose of the research to the participants and asked for their voluntary participation. They were emphatically assured that the responses are confidential and only the researchers would be viewing the responses. Initially, we received 359 responses from 51 teams. Those employees were included in the analysis only if their managers or team leaders also rated them and that reduced the sample size to 307 respondents nested in 43 teams. Checking for a casual pattern in the supervisor rating and case-wise deletion of missing values (Schafer and Graham, 2002) reduced the sample size to 272. Further, after checking for a casual pattern in employee ratings and replacing missing values with the mean, the final sample size came to 258 employees in 41 teams.

\subsection{Measures}

Construct operationalization and definitions are given in Table II. The individual item of the constructs were rated on five point Likert scale (wherein, strongly disagree $=1$, and strongly agree $=5$ ). We adapted the instruments on professional role identity, knowledge helping, knowledge self-efficacy and knowledge sharing from McDearmon (2013), Mittal et al. (2018), Kankanhalli et al. (2005) and Bock et al. (2005), respectively. The items for the measuring instrument on prosocial knowledge effectiveness were adapted from Gray and Meister (2004) and Morgeson et al. (2010), whereas the items for the instruments to assess KSAs were developed from Faraj and Sproull (2000), Blader and Chen (2012) and Hofmann et al. (2009). In this study, we controlled for age, gender (Maurer, 2001) and team characteristics (Lin and Huang, 2010; Kankanhalli et al., 2005). The measuring instruments and their items used in this study are presented in the Appendix.

\section{Results}

\subsection{Reliability and validity}

We calculated reliability and validity to check for the psychometric properties of the measuring instruments. The reliability coefficients (Cronbach's alpha) for KSAs (0.698), knowledge sharing (0.784), knowledge helping (0.882), prosocial knowledge effectiveness (0.772), knowledge self-efficacy (0.80) and professional role identity (0.745) indicated good reliability of the measures used. Table IV depicts means, standard deviations, intercorrelations and reliabilities of the measuring instruments.

Adequacy of the measurement model was examined using LISREL software and model fit was obtained. Our hypothesized six-factor model provided a good fit for the data, wherein the Comparative fit index $(\mathrm{CFI})=0.96$, Incremental fit index $(\mathrm{IFI})=0.96$, Root mean square error of approximation statistic (RMSEA) $=0.08$, Standardized root mean square residual statistic $(\mathrm{SRMR})=0.059$ and $\left.\mathrm{CMIN}\left[\left(\chi^{2}\right) / \mathrm{df}=2.68\right)\right]$ were found. A model typically

Table IV Means, SD, reliabilities and inter-correlations of variables $(n=258)$

\begin{tabular}{lcccccccc} 
& & & \multicolumn{8}{c}{ Variables } & \\
Variables & Mean & $S D$ & KSAs & $K S$ & KH & KBE & KSE & PRI \\
\hline KSAs & 2.52 & 0.82 & 0.698 & & & & \\
Knowledge sharing (KS) & 3.99 & 0.70 & $0.323^{* *}$ & 0.784 & & & \\
Knowledge helping(KH) & 4.07 & 0.64 & $0.408^{* *}$ & $0.701^{* *}$ & 0.882 & & \\
Prosocial knowledge & 3.89 & 0.69 & $0.424^{* *}$ & $0.646^{* *}$ & $0.591^{* *}$ & 0.772 & & \\
effectiveness (PKE) & & & & & & & & \\
Knowledge self-efficacy (KSE) & 3.83 & 0.90 & $0.282^{* *}$ & $0.392^{* *}$ & $0.521^{* *}$ & $0.371^{* *}$ & 0.8 & \\
Professional role identity (PRI) & 4.12 & 0.70 & $0.340^{* *}$ & $0.509^{* *}$ & $0.627^{* *}$ & $0.477^{* *}$ & $0.539^{* *}$ & 0.745
\end{tabular}

Notes: Italic values in the diagonal of the correlation matrix represent Cronbach's alpha reliabilities; ${ }^{*} p<0.05 ;{ }^{* *} p<0.01$ 
considered as fitting the data well has a $\chi 2$ /df ratio below 3 , a CFI value of 0.90 or above, a RMSEA value of 0.08 or less and a SRMR value of 0.06 or less (Kline, 2005). Therefore, our measurement model fits the data well. All factor loadings were statistically significant and their loading onto the corresponding latent variables exceeded the conventional cut-off value of 0.6, which were further used in Preacher and Hayes' (2008) bootstrap approach of moderated-mediation.

We observed the typically high correlations between dimensions of knowledge sharing and knowledge helping; between prosocial knowledge effectiveness and knowledge sharing; and between professional role identity and knowledge helping.

Therefore, we compared the default measurement model with the models that collapsed across those dimensions. The obtained fit statistics (Table $V$ ) demonstrated the fit superiority of the hypothesized model over competing models (Alfes et al., 2013). The models combining dimensions provided a significantly worse fit to the data indicating strong evidence of the discriminant validity (Table V).

Harman's single-factor test was used to check common method bias. The results revealed six factors with an eigenvalue greater than one criterion and no single factor explained most of the variance (i.e. the variances explained ranged from 7.72 to 20.63 per cent). As a single factor did not emerge and the first factor accounted for a fraction of the variance, we safely concluded that the results would not be inflated due to the existence of common method variance in the data. In addition to the Harman's single factor test, we used the marker-variable technique (Malhotra et al., 2006) to assess for the issue related to common method variance (CMV). In this study, we used political skill as the marker variable. The marker variable $(\mathrm{rM})$ had mean absolute correlation of 0.026 with the other substantive variables. The CMV-adjusted correlation ( $\mathrm{rA}$ ) was 0.266 and uncorrected bivariate correlation ( $\mathrm{rU}$ ) was 0.289 . Furthermore, we examined the impact of $\mathrm{CMV}$ on the magnitude and significance of correlation and found that the CMV-adjusted correlations were not significantly different from the unadjusted correlations (Malhotra et al., 2006) and that suggests the CMV was not an issue in the dataset of the study.

\subsection{Analysis and results}

We adopted the quantitative research design to test the hypotheses using self-rated surveybased research questions based on five point scales. Structural equation modelling (SEM) has limitations to analyze the moderated-mediation relationships (Hair et al., 2009). Therefore, instead of the SEM approach throughout, we used hierarchal linear regression with a CFA for testing hypotheses (Hair et al., 2009). For the regression analysis, all the independent variables were measured and analyzed at an individual level. The prosocial knowledge effectiveness of a team member (dependent variable) can best be assessed by his/her supervisor only; thus, it was measured at the supervisor level and analysed at an individual level. The unit of measurement and the level of analysis were consistent with previous studies that recommended keeping the theoretical consistency among levels (Hitt et al., 2007).

Table V Confirmatory factor analysis details of the measures

\begin{tabular}{lcrr} 
Model and structure & Chi square/df & Chi square (df) & Delta chi square (df) \\
\hline 1. Six factors: KSAs, KS, KH, PKE, KSE and PRI & 2.68 & $696.8(260)$ & \\
2. Five factors: KSAs, KS-KH combined, PKE, KSE and PRI & 3.53 & $935.45(265)$ & $238.65(5)^{* * *}(2 \mathrm{vs} 1)$ \\
3. Five factors: KSAs, KH, PKE-KS combined, KSE and PRI & 3.67 & $972.55(265)$ & $275.75(5)^{* * *}(3 \mathrm{vs} 1)$ \\
4. Five factors: KSAs, PKE, KS, KSE and PRI-KH combined & 3.91 & $1,036.15(265)$ & $339.35(5)^{* * *}(4 \mathrm{vs} 1)$ \\
Note: ${ }^{* * *} p<0.001$ & & &
\end{tabular}


Considering the possibility for some supervisors rating their employees higher, we checked for possible cross-level effects. However, the previous literature suggests that supervisor-level effects are less likely to influence the individual social exchanges and helping behaviours (De Jong et al., 2007). Hence, we used variance partitioning of levels for checking possible supervisor-level effects on the dependent variable and found a negligible effect (less than 2 per cent). Further, we conducted the bootstrap approach to examine the implied mediation as a more robust test of indirect effects (Preacher and Hayes, 2008). The items with factor loading $>0.6$ were allotted weights on the basis of their factor loadings and others a weight of 0 (cross-loaded items would automatically, therefore, get a weight of 0 ). The weighted average was calculated for each variable. These scores representing the variables' values were then used in the Preacher and Hayes (2008) macro (for mediation and moderated-mediation of IBM SPSS 20.0 statistical package) for further data analysis.

\subsection{Moderation effects}

We looked for possible cross-level effects before hypothesis testing. Though past literature suggests that supervisor-level effects are less likely to influence the individual social exchanges and helping behaviours (De Jong et al., 2007), the study used variance partitioning to check for possible supervisor-level effects on the dependent variable. The findings indicated miniscule 2.4 per cent (insignificant) supervisor/team variance on prosocial knowledge effectiveness.

$\mathrm{H} 1 \mathrm{a}$ and $\mathrm{H} 2 \mathrm{a}$ specified that knowledge self-efficacy interacted with professional role identity and KSAs, respectively, to predict knowledge sharing. Table VI (refer to Model 3a) presents the results of hierarchical linear regression analysis (also depicted in Figure 2). The findings indicated that people having higher professional role identity shared knowledge more when they had high self-efficacy and shared less when they had low self-efficacy. H1a was found to be significant at $p<0.05$ level, and H2a was found to be non-significant. Therefore, among the proposed interaction effects, the interaction between knowledge self-efficacy and professional role identity to predict knowledge sharing was found to be significant only, giving support for this relationship, whereas the interaction effect between knowledge selfefficacy and KSAs was non-significant.

$H 1 b$ and $H 2 b$ specified that knowledge self-efficacy interacted with professional role identity and KSAs, respectively, to predict knowledge helping. Table VI (refer to Model 3b) presents the results of hierarchical linear regression analysis. Figure 3 depicts that people

Table VI Hierarchical linear regression results of direct and interaction effects for dependent variables $(n=258)$

\begin{tabular}{|c|c|c|c|c|c|c|}
\hline Independent variable & $\begin{array}{c}\text { Model 1a } \\
\text { Estimate }\end{array}$ & $\begin{array}{c}\text { Modedge sha } \\
\text { Estimate }\end{array}$ & $\begin{array}{l}\text { Model } 3 a \\
\text { Estimate }\end{array}$ & $\begin{array}{c}\text { Model 1b } \\
\text { Estimate }\end{array}$ & $\begin{array}{l}\text { owledge help } \\
\text { Model } 2 b \\
\text { Estimate }\end{array}$ & $\begin{array}{c}\text { Model 3b } \\
\text { Estimate }\end{array}$ \\
\hline \multicolumn{7}{|l|}{ Control variables } \\
\hline Team size & $0.04^{* *}$ & 0.006 & -0.003 & $0.06^{* * *}$ & $0.098^{*}$ & $0.101^{*}$ \\
\hline Age & $0.12^{* * *}$ & $0.09^{*}$ & 0.009 & $0.14^{* * *}$ & 0.070 & 0.050 \\
\hline Gender $^{a}$ & 0.19 & 0.033 & 0.045 & $0.26^{* * *}$ & 0.048 & 0.051 \\
\hline Virtual team members & $0.09^{* * *}$ & $0.1^{*}$ & 0.079 & 0.05 & -0.023 & -0.039 \\
\hline \multicolumn{7}{|l|}{ Main variables } \\
\hline Knowledge self-efficacy & & $0.129^{* *}$ & $0.107^{*}$ & & $0.224^{* * *}$ & $0.220^{* * *}$ \\
\hline Professional role identity & & $0.384^{* * *}$ & $0.424^{* * *}$ & & $0.441^{* * *}$ & $0.467^{* * *}$ \\
\hline KSAs & & $0.112^{*}$ & $0.141^{* *}$ & & $0.129^{* *}$ & $0.131^{* *}$ \\
\hline \multicolumn{7}{|l|}{ Interaction terms } \\
\hline $\mathrm{KSE} \times \mathrm{KSAS}$ & & & -0.088 & & & -0.012 \\
\hline $\mathrm{KSE} \times \mathrm{PRI}$ & & & $0.105^{* *}$ & & & $0.068^{*}$ \\
\hline$R^{2}$ overall model & 0.11 & 0.30 & 0.31 & 0.13 & 0.46 & 0.47 \\
\hline
\end{tabular}




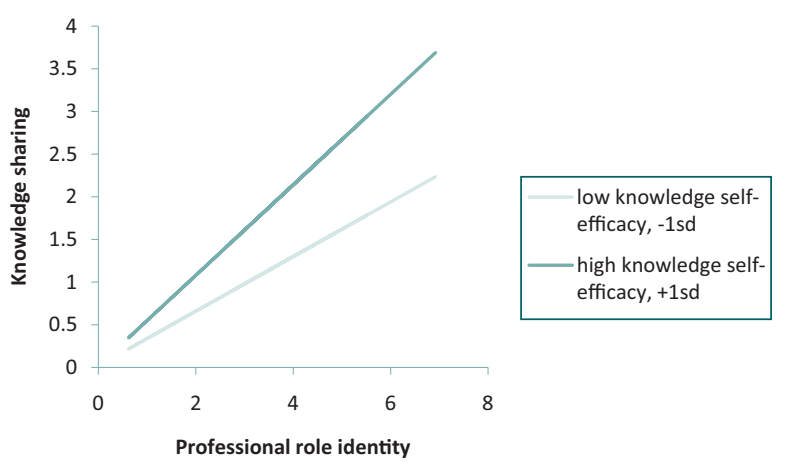

Figure 3 Regression slopes for knowledge helping, knowledge self-efficacy as moderator

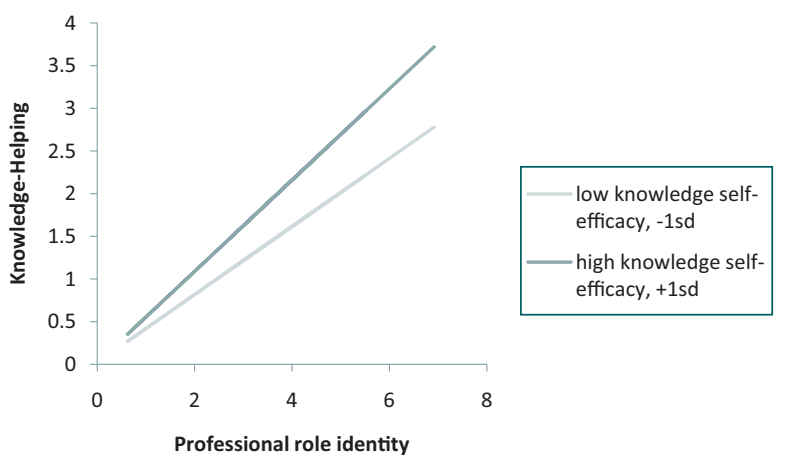

having higher professional role identity participate in knowledge helping more when they have high self-efficacy and less when they have low self-efficacy. Only H1b was found to be significant at $p<0.1$ level, but $H 2 b$ was non-significant. Therefore, among the proposed interaction effects, the interaction of knowledge self-efficacy and professional role identity to predict knowledge helping was found to be significant only, giving support for this relationship; whereas the interaction effect between knowledge self-efficacy and KSAs was non-significant.

\subsection{Mediation and moderated-mediation effects}

As shown in Figure 1, $\mathrm{H} 3 \mathrm{a}, \mathrm{H} 3 \mathrm{~b}, \mathrm{H} 4 \mathrm{a}, \mathrm{H} 4 \mathrm{~b}, \mathrm{H} 5 \mathrm{a}$ and $\mathrm{H} 5 \mathrm{~b}$ implied a mediated model where the relationships of professional role identity, knowledge self-efficacy and KSAs with prosocial knowledge effectiveness were mediated by knowledge sharing and knowledge helping. To explore the statistical significance of these relationships, the three-step process of mediation analysis, as outlined by Baron and Kenny (1986), was adopted and the results are presented in Table VII. The first two models in Table VII regressed each of the mediators knowledge sharing and knowledge helping onto three independent variables: professional role identity, knowledge self-efficacy and KSAs. As consistent with the hypothesis testing, each of professional role identity, knowledge self-efficacy, and KSAs significantly predicted each of knowledge sharing and knowledge helping. Model 3a in Table VII regressed the main independent variables professional role identity, knowledge self-efficacy and KSAs onto prosocial knowledge effectiveness. All three independent variables significantly 
Table VII Hierarchical linear regression results for investigation of implied mediation

\begin{tabular}{|c|c|c|c|c|}
\hline Independent variable & $\begin{array}{c}\text { Model 1: } \\
\text { knowledge sharing } \\
\text { Estimate }\end{array}$ & $\begin{array}{l}\text { De } \\
\text { Model 2: } \\
\text { knowledge helping } \\
\text { Estimate }\end{array}$ & $\begin{array}{l}\text { dent variables } \\
\text { Model 3a: prosocial } \\
\text { knowledge effectiveness } \\
\text { (PKE) } \\
\text { Estimate }\end{array}$ & $\begin{array}{c}\text { Model 3b: prosocial } \\
\text { knowledge effectiveness } \\
\text { (PKE) } \\
\text { Estimate }\end{array}$ \\
\hline \multicolumn{5}{|l|}{ Control variables } \\
\hline Team size & 0.006 & $0.098^{*}$ & -0.011 & -0.029 \\
\hline Age & $0.09^{*}$ & 0.070 & 0.023 & 0.011 \\
\hline Gender $^{a}$ & 0.033 & 0.048 & 0.043 & 0.021 \\
\hline Virtual team members & $0.1^{*}$ & -0.023 & 0.101 & 0.062 \\
\hline \multicolumn{5}{|l|}{ Main variables } \\
\hline Knowledge self-efficacy & $0.129^{* *}$ & $0.224^{* * *}$ & $0.112^{*}$ & 0.023 \\
\hline Professional role identity & $0.384^{* * *}$ & $0.441^{* * *}$ & $0.310^{* * *}$ & 0.078 \\
\hline KSAs & $0.112^{*}$ & $0.129^{* *}$ & $0.236^{* * *}$ & $0.170^{* * *}$ \\
\hline \multicolumn{5}{|l|}{ Mediators } \\
\hline Knowledge Sharing & & & & $0.428^{* * *}$ \\
\hline Knowledge Helping & & & & $0.150^{* *}$ \\
\hline
\end{tabular}

predicted prosocial knowledge effectiveness. Model $3 \mathrm{~b}$ added the main effects of the mediators to the equation of Model 3a. The beta weights associated with the independent variables were reduced. Specifically, the beta weights for professional role identity were reduced from $\beta=0.310$ ( $\mathrm{p}<0.001$ ) to $\beta=0.078$ (insignificant). The beta weights for knowledge self-efficacy were reduced from $\beta=0.112(\mathrm{p}<0.05)$ to $\beta=0.023$ (insignificant). The beta weights for KSAs were reduced from $\beta=0.236(\mathrm{p}<0.001)$ to $\beta=$ 0.170 ( $\mathrm{p}<0.001$ ). This rendered support for $\mathrm{H} 3 \mathrm{a}, \mathrm{H} 3 \mathrm{~b}, \mathrm{H} 4 \mathrm{a}, \mathrm{H} 4 \mathrm{~b}, \mathrm{H} 5 \mathrm{a}$, and H5b.

Table VIII presents the results for the indirect effect and were found to be significant and support $\mathrm{H} 3 \mathrm{a}, \mathrm{H} 3 b, \mathrm{H} 4 \mathrm{a}, \mathrm{H} 4 \mathrm{~b}, \mathrm{H} 5 \mathrm{a}$ and $\mathrm{H} 5 \mathrm{~b}$. In addition, the total indirect effects of mediators were significant for each of professional role identity, knowledge self-efficacy, and KSAs. The moderated-mediation results, as shown in Row 4 of Table VIII, reveal support for $\mathrm{H} 6 \mathrm{a}$ and $\mathrm{H} 6 \mathrm{~b}$, indicating that there is an indirect relationship between the interaction term of professional role identity $X$ knowledge self-efficacy and prosocial knowledge effectiveness through knowledge exchange. The knowledge self-efficacy and KSAs interaction term did not have a significant direct relationship with knowledge exchange ( $\mathrm{H} 2 \mathrm{a}$ and $\mathrm{H} 2 \mathrm{~b}$ was earlier rejected). Thereby implying rejection of $\mathrm{H} 7 \mathrm{a}$ and $\mathrm{H} 7 \mathrm{~b}$, that there is no moderation on indirect relationship with prosocial knowledge effectiveness.

\subsection{Post hoc analysis}

We separated the two dimensions of prosocial knowledge effectiveness, team learning and team leadership. We found that team learning was more strongly predicted by knowledge

Table VIII Bootstrap results for indirect effects

\begin{tabular}{|c|c|c|c|c|c|c|c|c|c|}
\hline \multirow[b]{4}{*}{ Independent variable } & \multicolumn{9}{|c|}{ Indirect effects of IV on DV through proposed mediators (ab paths) } \\
\hline & \multirow{2}{*}{\multicolumn{3}{|c|}{ Knowledge Sharing }} & \multirow{2}{*}{\multicolumn{3}{|c|}{ Knowledge Helping }} & \multirow{2}{*}{\multicolumn{3}{|c|}{$\begin{array}{l}\text { Total } \\
\text { Confidence interval }\end{array}$}} \\
\hline & & & & & & interval & & & \\
\hline & Estimate & Lower & Upper & Estimate & Lower & Upper & Estimate & Lower & Upper \\
\hline KSAs & 0.04 & 0.01 & 0.08 & 0.02 & 0.00 & 0.05 & 0.06 & 0.02 & 0.10 \\
\hline Knowledge self-efficacy & 0.05 & 0.00 & 0.10 & 0.03 & 0.01 & 0.06 & 0.07 & 0.02 & 0.13 \\
\hline Professional role identity & 0.15 & 0.09 & 0.22 & 0.06 & 0.01 & 0.13 & 0.21 & 0.14 & 0.30 \\
\hline $\mathrm{PRI} \times \mathrm{KSE}$ & 0.05 & 0.00 & 0.12 & 0.02 & 0.00 & 0.05 & 0.07 & 0.01 & 0.14 \\
\hline
\end{tabular}


sharing $(\beta=0.57, \mathrm{p}<0.01)$ than knowledge helping $(\beta=0.13, \mathrm{p}<0.05)$. Team leadership was more strongly predicted by knowledge helping $(\beta=0.34, \mathrm{p}<0.01)$ than knowledge sharing $(\beta=0.26, \mathrm{p}<0.01$ ). Further analysis using bootstrap approach (sampling 1,000 bootstrapped cases at 95 per cent Confidence Interval) advocated by Preacher and Hayes (2008) revealed that team leadership was better explained by psychosocial capital (estimated indirect effect was 0.08) than human capital (estimated indirect effect was 0.02) through the path of knowledge helping. It was further observed that team learning was better explained by human capital (estimated indirect effects was 0.09) than psychosocial capital (estimated indirect effects was 0.08) through the path of knowledge sharing. Therefore, the inference may be drawn that there existed two dominant process models of prosocial knowledge effectiveness:

1. the process model via distal dimension of individual capital (psychosocial capital), informal process (knowledge helping) and knowledge effectiveness (team leadership); and

2. the process model of proximal dimension of individual capital (human capital), formal process (knowledge sharing) and knowledge effectiveness (team learning).

The detailed implications are discussed in the next section.

\section{Discussion}

\subsection{Summary of the findings}

The present study specifically examined the roles of knowledge sharing and knowledge helping in governing prosocial knowledge effectiveness (team learning and team leadership). All three aspects associated with human and psychosocial capital were considered: KSAs (capability), reason and valence of using KSAs for specific purposes (motivation) and confidence in relevance of one's capability for self and others (efficacy). The results indicated five findings of major significance and interest. First, knowledge sharing and knowledge helping were both found to be the significant link through which KSAs and their psychosocial aspects (professional role identity, and knowledge selfefficacy) significantly predicted prosocial knowledge effectiveness. Second, professional role identity and knowledge self-efficacy exhibited full mediation through knowledge exchange, whereas KSAs exhibited partial mediation. Third, the study examined the twoway interactions between knowledge self-efficacy and professional role identity and between knowledge self-efficacy and KSAs. Only the latter interaction was found to be significant for knowledge exchange. Fourth, all the three factors (capability, motivation, and efficacy) predicted knowledge helping more strongly than knowledge sharing. Fifth, both knowledge sharing and knowledge helping were found to be the full mediators. They were also found as the necessary links between human and psychosocial capital and knowledge-based effectiveness.

\subsection{Theoretical implications}

All the three aspects of human and psychosocial capital - capability, motivation and efficacy - were measured through KSAs, professional role identity and knowledge selfefficacy, respectively. Our findings suggested that all three aspects were significant predictors of both knowledge sharing and knowledge helping. Human and psychosocial capital were found to have stronger associations with knowledge helping than knowledge sharing. These findings have important implications for the nature and impact of formal and informal knowledge processes in teams (Foss et al., 2010). This implies that the nature of social involvement in knowledge helping provides higher meaning and significance to people vis-à-vis getting involved in knowledge sharing. Therefore, people are more likely to utilize their limited resources towards participating in informal 
processes knowledge helping. Knowledge sharing is a routine and formal task that lies within the in-role scope, whereas knowledge helping requires prosocial efforts (Grant and Ashford, 2008), which are informal/extra-role in nature. Knowledge helping provides greater significance and meaning to people because of its higher impact. Therefore, individuals who are capable, motivated, and confident in their KSAs are more eager to help others (Grant and Ashford, 2008).

Another interesting finding was on the relative roles of capability, motivation and efficacy of KSAs. Professional role identity and knowledge self-efficacy were found to be strong predictors of knowledge-based social exchanges. On the other hand, KSAs were strong direct predictors of prosocial knowledge effectiveness. Prior research has found that capability has a direct relationship with certain aspects of effectiveness (Schmidt and Hunter, 2004). Therefore, we suggest that capability is important in the case of effectiveness (Schmidt and Hunter, 2004, 1998; Ree and Carretta, 1998), whereas motivation and efficacy are important in social exchanges (Parker et al., 2010; Grant, 2008). The findings are in line with the previous literature on human and social capital that efficacy and motivation are distal or indirect indicators of performance, whereas KSAs are proximal or direct indicators of performance (Van Iddekinge et al., 2009).

This study also examined mediator roles of knowledge sharing and knowledge helping in the relationship between human and psychosocial capital and prosocial knowledge effectiveness. It was found that both forms of knowledge exchanges were the important governing mechanisms of human and psychosocial capital that resulted in the effectiveness. This indicates that social exchanges (knowledge helping and knowledge sharing) have two avenues of complementary but unique choices through which human and psychosocial capital are used for team learning and team leadership. It is the mix of reciprocal/reactive and altruistic/proactive exchanges that drive individual choices for prosocial knowledge effectiveness. Our findings are in line with the latest conceptual framework of Sedighi et al. (2016). We add to their work by developing and testing a moderated-meditation empirical model of formal and informal mechanisms of knowledge exchanges and its antecedents and outcomes. Moreover, our results are indicative of strong mediation, which implies that knowledge exchanges are the important and necessary outlay for capability, motivation, and efficacy of KSAs to be effective. Knowledge sharing and knowledge helping were also found to be the full mediators. Both knowledge sharing (task-focussed routine activities), which represents a formal mechanism, and knowledge helping (person-focussed developmental activities), which represents an informal mechanism, are necessary for collective learning to take place (Foss et al., 2010). The present study adds to the work of Serenko and Bontis (2016) on knowledge-based social exchanges by aligning formal and informal mechanisms along with motives (reciprocity and altruism) of knowledge-based social exchanges.

Sedighi et al. (2016) and Serenko and Bontis (2016) based their work on differentiating knowledge exchanges on motivation and social exchanges respectively. However, neither of these studies (including any other study to the best of our knowledge) explore the loci of these knowledge exchanges by matching the strength of their relationship with antecedents and outcomes. In this direction, post-hoc analysis revealed that knowledge helping governs team leadership more strongly than knowledge sharing; and knowledge sharing governs team learning more strongly than knowledge helping. There is a mix of formality and informality in team learning, whereas team leadership is an informal aspect of prosocial effectiveness. Therefore, team leadership was found to be strongly governed by an informal knowledge exchange mechanism in the form of knowledge helping, whereas team learning was found to be strongly governed by knowledge sharing, which is a mix of both formal and informal knowledge exchange 
mechanisms in the team. Even the two strong indirect links (psychosocial capital, knowledge helping and team leadership, human capital, knowledge sharing and team learning) could be explained on the basis of differentiating human and psychosocial capital on their formal/proximal and informal/distal natures respectively (Van Iddekinge et al., 2009). Therefore, matching motive or mechanism of knowledge exchanges are based on overall attitude/trait matching principle in which the intermediate mechanism or process matches with the respective antecedents and outcomes (Fishbein and Ajzen's, 1974).

Psychosocial capital is mainly interpersonal in nature and therefore relies mainly on informal knowledge exchange (knowledge helping) to govern team leadership. KSAs, on the other hand, have higher formalization, as they include formal education and training, work experience and access to organizational resources. Therefore, KSAs rely mainly on formal mechanisms of knowledge in the form of knowledge sharing to govern team leadership, which contains both formal and informal aspects. This has important implications in understanding the formal and informal design elements in teams. One important theoretical implication lies in formal processes matching with formal outcomes and informal processes matching with informal outcomes (Pemsel et al., 2016; Laursen and Foss, 2014). Second, formal and informal knowledge processes and outcomes are not fully separate, rather they have considerable cross influences.

\subsection{Managerial implications}

The present study focuses on how one's KSAs and their psychosocial aspects (motivation and self-efficacy) bring others-oriented effectiveness in a team context through knowledge exchange. This research model is highly relevant to the collective learning process of the organization. The elements of the proposed model can be used by managers to understand the process through which employees promote team learning and its boundary conditions. The study highlights that KSAs and their psychosocial aspects are complementary to others-oriented effectiveness. Therefore, focussing independently on KSAs may not promote collective learning in the organization. Unfortunately, only KSAs and not psychosocial aspects are given due priority in the organization. To be precise, our findings suggest that team learning and team leadership are fostered when KSAs and their psychosocial aspects are applied in tandem through knowledge exchanges. This means that managers should focus on the right mix of personal and social competencies of employees for collective learning and team leadership.

Furthermore, it was found that individuals with professional mindsets are more sure of their competencies; and are therefore better equipped to apply their competencies towards knowledge exchange and knowledge-based effectiveness. So organizations should focus towards building a culture of professionalism and nurturing professional mindsets among employees. Our findings suggest employees' knowledge self-efficacy is important in team learning and team leadership. As the previous literature suggests, knowledge self-efficacy can be enhanced by training and useful feedback to employees (Lin, 2007); therefore, managers must encourage training and provide useful feedback to employees.

Organizations tend to hire, promote, and encourage individuals with high expertise in domain knowledge. Our findings suggest that organizational hiring and promotion policies should not over encourage the culture of expertise. Effective and valuable use of expertise in team learning requires active employee participation. Efforts to foster the culture of informal knowledge exchanges in teams are necessary so that individuals with high expertise act as team leaders and use their expertise for team learning. In traditional organizations, where there are leaders at multiple hierarchies, functions of collective orientations are taken by them. The present study highlights the importance of team 
leadership. It becomes more important in the case of knowledge-intensive organizations which are flatter or have autonomous work cultures (Wu, 2015). Such organizations should start focussing on rewarding/recognizing contributions which have much larger/collective orientations along with individual performance.

One's knowledge should be transferred for effective collective learning. A mix of both selfand others-oriented knowledge exchange was found responsible for team learning and team leadership. Managers should not only promote perceptions of reciprocal benefits among knowledge workers, but also duly recognize and encourage others-oriented social exchanges in the form of knowledge helping. A team should have the mindset to promote others-oriented proactive behaviours rather than only reactive behaviours, as focussing too much on quid pro quo may eventually create bottlenecks in team learning. In fact, we suggest that both knowledge sharing (reciprocal) and knowledge helping (others-oriented and proactive in nature) should be encouraged to bring out optimum self- and othersoriented effectiveness.

Recently, the work design literature once again has started giving importance to the social considerations in work design. It has been suggested that the nature of interactions among team members should be more frequent, direct, and based on activities that are more impactful. These informal social elements provide greater significance and meaning to the social interactions and the overall activities associated with them. Organizations should design work roles in teams for fostering interactions in both routine and highly significant tasks. These informal social elements of work are closely associated with the feelings of both altruism and reciprocity in knowledge exchanges (Grant,2007), wherein incentive design and governance mechanisms are solely known to promote reciprocal/formal knowledge exchanges (Laursen and Foss, 2014). Therefore, depending upon the nature of work and structure, setting the right combination of formal and informal elements is important for the design.

\subsection{Limitations and direction for future research}

We have already highlighted the procedures adopted from Podsokoffet al. (2003) to reduce common method bias in the method section. Self-rated measures have limitations, but there are also advantages. Self-ratings are the best way to capture motivations, attitudes, and perceptions accurately (Parker and Collins, 2010) and, in fact, largely, it is the only way other than conditioning methods used in experimental designs. In addition, the relationships between the variables rated by the common source have complicated interactions that cannot be attributed to common method variance (Evans, 1985). Thus, it appears that we could reduce common method variance considerably. However, it remains a concern for the survey-based research method always.

The team managers rated the aspects of the knowledge effectiveness (the dependent variable) used in the study, and therefore, it is free from common method bias. Moreover, some of the variables in the study, like KSAs and number of virtual team members, involved factual data (i.e. job experience and fulfilling an official work role), which are not subject to common method concerns (Doty and Glick, 1998; Podsakoff and Organ, 1986). However, future studies can look for innovative research design to overcome the shortcomings by designing multitrait-multimethod research.

Lastly, limitation lies in the generalizibility of results to teams who have hierarchal reporting structures and limited role of knowledge in their production activities. Future studies can modify the proposed model for its applicability in other types of teams. Though the focus of the present study was primarily on knowledge aspects, the overall theme of relatedness and formal and informal processes may also be applicable in aspects of work other than knowledge. 
Of possible scope to future studies could be the use of knowledge helping as a possible mechanism of collective learning in other cultures. It may be possible that proactive helping may not be observable in individualistic cultures and may be a phenomenon of collectivistic cultures. Whether proactive helping behaviours is a culture-specific phenomenon or not requires further exploration. Replicating the same study with suitable adaptations in western cultures should use the boundary conditions of this phenomenon. Furthermore, we conducted this study from organizational behaviour perspective in outlining the process of collective learning. We suggest that future studies should look through other possible behavioural science disciplinary lenses to explore processes through which collective learning takes place. It would also be useful to examine the situational factors that promote or restrain the effectiveness of KSAs. Moreover, it would be fruitful to examine the relative roles of domain-specific KSAs and generic KSAs as well.

\section{References}

Acharya, A., Singh, S.K., Pereira, V. and Singh, P. (2018), "Big data, knowledge co-creation, and decision making in fashion industry", International Journal of Information Management, Vol. 42, pp. 90-101.

Al Ahbabi, S., Singh, S.K., Gaur, S.S. and Balasubramanian, S. (2018), "Employee perception of impact of knowledge management practices on public sector performance", Journal of Knowledge Management, available at: https://doi/full/10.1108/JKM-08-2017-0348

Al Ahbabi, S., Singh, S.K., Gaur, S.S. and Balasubramanian, S. (2017), "A knowledge management framework for enhancing public sector performance", International Journal of Knowledge Management Studies, Vol. 8 Nos 3/4, pp. 329-350.

Alfes, K., Shantz, A.D., Truss, C. and Soane, E.C. (2013), "The link between perceived human resource management practices, engagement and employee behaviour: a moderated mediation model", The International Journal of Human Resource Management, Vol. 24 No. 2, pp. 330-351.

Ali, I., Musawir, A.U. and Ali, M. (2018), "Impact of knowledge sharing and absorptive capacity on project performance: the moderating role of social processes", Journal of Knowledge Management, Vol. 22 No. 2, pp. 453-477.

AIShaima, T.H., Singh, S.K., Farouk, S. and Sohal, A.S. (2016), "Knowledge sharing enablers, processes and firm innovation capability: a study", Journal of Workplace Learning, Vol. 28 No. 8, pp. 484-495.

Ashforth, B.E. and Johnson, S.A. (2001), "Which hat to wear? The relative salience of multiple identities in organizational contexts", in Hogg, M.A. and Terry, D.J. (Eds), Social Identity Processes in Organizational Contexts, Psychology Press, Philadelphia, PA, pp. 32-48.

Baer, M. and Oldham, G.R. (2006), "The curvilinear relation between experienced creative time pressure and creativity: moderating effects of openness to experience and support for creativity", Journal of Applied Psychology, Vol. 91 No. 4, pp. 963-970.

Bandura, A. (1997), Self-Efficacy: The Exercise of Control, W.H. Freeman, New York, NY.

Baron, R.M. and Kenny, D.A. (1986), "The moderator-mediator variable distinction in social psychological research: conceptual, strategic, and statistical considerations", Journal of Personality and Social Psychology, Vol. 51 No. 6, pp. 1173-1182.

Becker, G.S. (1964), Human Capital, Columbia University Press, New York, NY.

Bird, B. (1988), "Implementing entrepreneurial ideas: the case for intention", Academv of Management Review, Vol. 13 No. 3, pp. 442-453.

Blader, S.L. and Chen, Y.R. (2012), "Differentiating the effects of status and power: a justice perspective", Journal of Personality and Social Psychology, Vol. 102 No. 5, pp. 994-1014.

Bock, G.W., Zmud, R.W., Kim, Y.G. and Lee, J.N. (2005), "Behavioural intention formation in knowledgesharing: examining the roles of extrinsic motivators, social-psychological forces, and organizational climate", MIS Quarterly, Vol. 29 No. 1, pp. 87-111.

Bunderson, J.S. and Reagans, R.E. (2011), "Power, status, and learning in organizations", Orqanization Science, Vol. 22 No. 5, pp. 1182-1194. 
Chen, G., Gully, S.M. and Eden, D. (2001), "Validation of a new general self-efficacy scale", Organizational Research Methods, Vol. 4 No. 1, pp. 62-83.

Chou, H.W., Lin, Y.H., Lu, H.S., Chang, H.H. and Chou, S.B. (2014), "Knowledge sharing and ERP system usage in post-implementation stage", Computers in Human Behaviour, Vol. 33, pp. 16-22.

Constant, D., Sproull, L. and Kiesler, S. (1996), "The kindness of strangers: the usefulness of electronic weak ties for technical advice", Organization Science, Vol. 7 No. 2, pp. 119-135.

Cropanzano, R. and Mitchell, M.S. (2005), "Social exchange theory: an interdisciplinary review", Journal of Management, Vol. 31 No. 6, pp. 874-900.

De Jong, S.B., Van der Vegt, G.S. and Molleman, E. (2007), "The relationships among asymmetry in task dependence, perceived helping behaviour, and trust”, Journal of Applied Psvchologv, Vol. 92 No. 6, pp. 1625-1637.

DeRue, D.S. and Ashford, S.J. (2010), "Who will lead and who will follow? A social process of leadership identity construction in organizations", Academv of Management Review, Vol. 35 No. 4, pp. 627-647.

DeRue, D.S. and Morgeson, F.P. (2007), "Stability and change in person-team and person-role fit over time: the effects of growth satisfaction, performance, and general self-efficacy", Journal of Applied Psychologv, Vol. 92 No. 5, pp. 12-42.

Doty, D.H. and Glick, W.H. (1998), "Common methods bias: does common methods variance really bias results?", Organizational Research Methods, Vol. 1 No. 4, pp. 374-406.

Duffield, S. and Whitty, S.J. (2016), "How to apply the systemic lessons learned knowledge model to wire an organisation for the capability of storytelling", International Journal of Project Management, Vol. 34 No. 3, pp. 429-443.

Evans, M.G. (1985), "A Monte Carlo study of the effects of correlated method variance in moderated multiple regression analysis", Organizational Behaviour and Human Decision Processes, Vol. 36 No. 3, pp. 305-323.

Faraj, S. and Sproull, L. (2000), "Coordinating expertise in software development teams", Management Science, Vol. 46 No. 12, pp. 1554-1568.

Fay, D. and Frese, M. (2001), "The concept of personal initiative: an overview of validity studies", Human Performance, Vol. 14 No. 1, pp. 97-124

Ferraris, A., Erhardt, N. and Bresciani, S. (2017), "Ambidextrous work in smart city project alliances: unpacking the role of human resource management systems", The International Journal of Human Resource Management, doi: 10.1080/09585192.2017.1291530.

Fishbein, M. and Ajzen, I. (1974), "Attitudes towards objects as predictors of single and multiple behavioral criteria”, Psvchological Review, Vol. 81 No. 1, pp. 59-74.

Foss, N.J., Husted, K. and Michailova, S. (2010), "Governing knowledge sharing in organizations: levels of analysis, governance mechanisms, and research directions", Journal of Management Studies, Vol. 47 No. 3, pp. 455-482

Foss, N.J., Pedersen, T., Reinholt Fosgaard, M. and Stea, D. (2015), "Why complementary HRM practices impact performance: the case of rewards, job design, and work climate in a knowledge-sharing context", Human Resource Management, Vol. 54 No. 6, pp. 955-976.

Freese, J., Rivas, S. and Hargittai, E. (2006), "Cognitive ability and Internet use among older adults", Poetics, Vol. 34 No. 4-5, pp. 236-249.

Garicano, L. and Wu, Y. (2012), "Knowledge, communication, and organizational capabilities", Organization Science, Vol. 23 No. 5, pp. 1382-1397

Grant, A.M. (2007), "Relational job design and the motivation to make a prosocial difference", Academy of Management Review, Vol. 32 No. 2, pp. 393-417.

Grant, A.M. (2008), "Does intrinsic motivation fuel the prosocial fire? Motivational synergy in predicting persistence, performance, and productivity", Journal of Applied Psychology, Vol. 93 No. 1, pp. 48-58.

Grant, A.M. (2012), "Giving time, time after time: work design and sustained employee participation in corporate volunteering", Academv of Management Review, Vol. 37 No. 4, pp. 589-615.

Grant, A.M. and Ashford, S.J. (2008), "The dynamics of proactivity at work", Behaviour, Vol. 28 No. 1, pp. 3-34. 
Gray, P.H. and Meister, D.B. (2004), "Knowledge sourcing effectiveness", Management Science, Vol. 50 No. 6, pp. 821-834.

Hair, J.F., Black, W.C., Babin, B.J. and Anderson, R.E. (2009), Multivariate Data Analysis, Vol. 7, Prentice Hall, Upper Saddle River, NJ.

Hall, H., Widen, G. and Paterson, L. (2010), "Not what you know, nor who you know, but who you know already: examining online information sharing behaviours in a blogging environment through the lens of social exchange theory", Libri, Vol. 60 No. 2, pp. 117-128.

Hitt, M.A., Beamish, P.W., Jackson, S.E. and Mathieu, J.E. (2007), "Building theoretical and empirical bridges across levels: multilevel research in management", Academy of Management Journal, Vol. 50 No. 6, pp. 1385-1399.

Hofmann, D.A., Lei, Z. and Grant, A.M. (2009), "Seeking help in the shadow of doubt: the sense-making processes underlying how nurses decide whom to ask for advice", Journal of Applied Psychology, Vol. 94 No. 5, pp. $1261-1274$.

Holzmann, V. (2013), "A Meta-analysis of brokering knowledge in project management", International Journal of Project Management, Vol. 31 No. 1, pp. 2-13.

Huang, M.C., Chiu, Y.P. and Lu, T.C. (2013), "Knowledge governance mechanisms and repatriate's knowledge sharing: the mediating roles of motivation and opportunity", Journal of Knowledge Management, Vol. 17 No. 5, pp. 677-694.

Huang, X., Hsieh, J.J. and He, W. (2014), "Expertise dissimilarity and creativity: the contingent roles of tacit and explicit knowledge sharing", Journal of Applied Psvchologv, Vol. 99 No. 5, pp. 816-830.

Humphrey, S.E., Nahrgang, J.D. and Morgeson, F.P. (2007), "Integrating motivational, social, and contextual work design features: a Meta-analytic summary and theoretical extension of the work design literature", Journal of Applied Psychologv, Vol. 92 No. 5, pp. 1332-1356.

Hunter, J.E. and Schmidt, F.L. (1996), "Intelligence and job performance: economic and social implications", Psychologv. Public Policy. and Law, Vol. 2 Nos 3/4, pp. 447-472.

Ibarra, H. (1999), "Provisional selves: experimenting with image and identity in professional adaptation", Administrative Science Quarterly, Vol. 44 No. 4, pp. 764-791.

Judge, T.A., Jackson, C.L., Shaw, J.C., Scott, B.A. and Rich, B.L. (2007), "Self-efficacy and work-related performance: the integral role of individual differences", Journal of Applied Psychologv, Vol. 92 No. 1, pp. 107-127.

Kammeyer-Mueller, J.D. and Judge, T.A. (2008), "A quantitative review of mentoring research: test of a model”, Journal of Vocational Behaviour, Vol. 72 No. 3, pp. 269-283.

Kankanhalli, A., Tan, B.C. and Wei, K.K. (2005), "Contributing knowledge to electronic knowledge repositories: an empirical investigation", MIS Quarterly, Vol. 29 No. 1, pp. 113-143.

Kirsch, L.J. (1996), "The management of complex tasks in organizations: controlling the systems development process", Organization Science, Vol. 7 No. 1, pp. 1-21.

Kline, R.B. (2005), Principles and Practice of Structural Equation Modelling, Guilford, New York, NY.

Laursen, K. and Foss, N.J. (2014), "Human resource management practices and innovation", in Dodgson, M., Gann, D.M. and Phillips, N. (Eds), The Oxford Handbook of Innovation Management, Oxford University Press, Oxford, pp. 506-529.

Levine, S.S. and Prietula, M.J. (2012), "How knowledge transfer impacts performance: a multilevel model of benefits and liabilities", Organization Science, Vol. 23 No. 6, pp. 1748-1766.

Lin, H.F. (2007), "Effects of extrinsic and intrinsic motivation on employee knowledge-sharing intentions", Journal of Information Science, Vol. 33 No. 2, pp. 135-149.

Lin, T.C. and Huang, C.C. (2010), "Withholding effort in knowledge contribution: the role of social exchange and social cognitive on project teams", Information and Management, Vol. 47 No. 3, pp. 188-196.

Liu, C.C., Liang, T.P., Rajagopalan, B., Sambamurthy, V. and Wu, J.C.H. (2012), "Knowledge sharing as social exchange: evidence from a Meta-analysis", Pacific Asia Journal of the Association for Information Systems, Vol. 3 No. 4, pp. 21-47. 
Loon, M. (2019), "Knowledge management practice system: theorising from an international Metastandard", Journal of Business Research, Vol. 94, pp. 432-441, available at: https://doi.org/10.1016/j. jbusres.2017.11.022

Lubinski, D. (2000), "Scientific and social significance of assessing individual differences: sinking shafts at a few critical points", Annual Review of Psychology, Vol. 51 No. 1, pp. 405-444.

McDearmon, J.T. (2013), "Hail to thee, our alma mater: alumni role identity and the relationship to institutional support behaviors", Research in Higher Education, Vol. 54 No. 3, pp. 283-302.

Malhotra, M.K. and Grover, V. (1998), "An assessment of survey research in POM: from constructs to theory", Journal of Operations Management, Vol. 16 No. 4, pp. 407-425.

Malhotra, N.K., Kim, S.S. and Patil, A. (2006), "Common method variance in IS research: a comparison of alternative approaches and a reanalysis of past research", Management Science, Vol. 52 No. 12, pp. 1865-1883.

Maurer, T.J. (2001), "Career-relevant learning and development, worker age, and beliefs about selfefficacy for development", Journal of Management, Vol. 27 No. 2, pp. 123-140.

Mittal, S., Sengupta, A. and Agarwal, N.M. (2018), "Knowledge-based proactive helping: developing and validating a scale", Journal of Manaqement and Organization, pp. 1-26, doi: 10.1017/jmo.2017.80.

Morgeson, F.P., DeRue, D.S. and Karam, E.P. (2010), "Leadership in teams: a functional approach to understanding leadership structures and processes", Journal of Management, Vol. 36 No. 1, pp. 5-39.

Nicolini, D. (2011), "Practice as the site of knowing: insights from the field of telemedicine", Organization Science, Vol. 22 No. 3, pp. 602-620.

North, R.J. and Swann, W.B. Jr (2009), "Self-verification 360': illuminating the light and dark sides, in Kwan, V. and Gaertner, L. (Eds), special issue for", Self and Identity, Vol. 8 Nos 2/3, pp. 131-146.

Ohly, S. and Fritz, C. (2007), "Challenging the status quo: what motivates proactive behaviour?", Journal of Occupational and Organizational Psychology, Vol. 80 No. 4, pp. 623-629.

Osterloh, M. and Frey, B.S. (2000), "Motivation, knowledge transfer, and organizational forms", Organization Science, Vol. 11 No. 5, pp. 538-550.

Ouchi, W.G. (1980), "Markets, bureaucracies, and clans", Administrative Science Quarterly, Vol. 25 No. 1, pp. 129-141.

Parker, S.K. and Collins, C.G. (2010), "Taking stock: integrating and differentiating multiple proactive behaviours”, Journal of Management, Vol. 36 No. 3, pp. 633-662.

Parker, S.K., Bindl, U.K. and Strauss, K. (2010), "Making things happen: a model of proactive motivation", Journal of Management, Vol. 36 No. 4, pp. 827-856.

Parker, S.K., Williams, H.M. and Turner, N. (2006), "Modelling the antecedents of proactive behaviour at work", The Journal of Applied Psychology, Vol. 91 No. 3, pp. 636-652.

Pemsel, S. and Müller, R. (2012), "The governance of knowledge in project-based organizations", International Journal of Project Management, Vol. 30 No. 8, pp. 865-876.

Pemsel, S., Müller, R., S., «. and derlund, J. (2016), "Knowledge governance strategies in project-based organizations", Long Range Planning, Vol. 49 No. 6, pp. 648-660.

Pemsel, S., Wiewiora, A., Mu, «ller, R., Aubry, M. and Brown, K. (2014), "A conceptualization of knowledge governance in project-based organizations", International Journal of Project Management, Vol. 32 No. 8, pp. 1411-1422.

Perlow, L. and Weeks, J. (2002), "Who's helping whom? Layers of culture and workplace behaviour", Journal of Organizational Behavior, Vol. 23 No. 4, pp. 345-361.

Podsakoff, P.M. and Organ, D.W. (1986), "Self-reports in organizational research: problems and prospects", Journal of Management, Vol. 12 No. 4, pp. 531-544.

Podsakoff, P.M., MacKenzie, S.B., Lee, J.Y. and Podsakoff, N.P. (2003), "Common method biases in behavioural research: a critical review of the literature and recommended remedies", Journal of Applied Psychologv, Vol. 88 No. 5, pp. 879-903

Preacher, K.J. and Hayes, A.F. (2008), "Asymptotic and re-sampling strategies for assessing and comparing indirect effects in multiple mediator models", Behaviour Research Methods, Vol. 40 No. 3, pp. 879-891. 
Quigley, N.R., Tesluk, P.E., Locke, E.A. and Bartol, K.M. (2007), "A multilevel investigation of the motivational mechanisms underlying knowledge sharing and performance", Organization Science, Vol. 18 No. 1, pp. 71-88.

Ree, M.J. and Carretta, T.R. (1998), "Computerized testing in the United States air force", International Journal of Selection and Assessment, Vol. 6 No. 2, pp. 82-89.

Reuber, A.R. and Fischer, E.M. (1994), "Entrepreneurs' experience, expertise, and the performance of technology-based firms", IEEE Transactions on Enqineering Management, Vol. 41 No. 4, pp. 365-374.

Schafer, J.L. and Graham, J.W. (2002), "Missing data: our view of the state of the art", Psychological Methods, Vol. 7 No. 2, pp. 147-177.

Schein, E.H. and Schein, E. (1978), Career Dynamics: Matching Individual and Organizational Needs, Vol. 24, Addison-Wesley, Reading, MA.

Schmidt, F.L. and Hunter, J. (2004), "General mental ability in the world of work: occupational attainment and job performance", Journal of Personality and Social Psychology, Vol. 86 No. 1, pp. 162-173.

Schmidt, F.L. and Hunter, J.E. (1998), "The validity and utility of selection methods in personnel psychology: practical and theoretical implications of 85 years of research findings", Psychological Bulletin, Vol. 124 No. 2, pp. 262-274.

Sedighi, M., Splunter, S.V., Brazier, F., Beers, C.V. and Lukosch, S. (2016), "Exploration of multi-layered knowledge sharing participation: the roles of perceived benefits and costs", Journal of Knowledge Management, Vol. 20 No. 6, pp. 1247-1267.

Serenko, A. and Bontis, N. (2016), "Understanding counterproductive knowledge behaviour: antecedents and consequences of intra-organizational knowledge hiding", Journal of Knowledge Management, Vol. 20 No. 6, pp. 1199-1224.

Singh, R. and Gupta, M. (2014), "Knowledge management in teams: empirical integration and development of a scale", Journal of Knowledge Management, Vol. 18 No. 4, pp. 777-794.

Singh, S.K., Pradhan, R.K., Panigrahy, N.P. and Jena, L.K. (2019), "Self-efficacy and workplace wellbeing: moderating role of sustainability practices", Benchmarking: An International Journal, available at: https://doi.org/10.1108/BIJ-07-2018-0219

Spitzmuller, M. and Van Dyne, L. (2013), "Proactive and reactive helping: contrasting the positive consequences of different forms of helping", Journal of Organizational Behavior, Vol. 34 No. 4, pp. 560-580.

Swann, W.B. Jr (1990), "To be adored or to be known? The interplay of self-enhancement and selfverification", in Higgins, E.T. and Sorrentino, R.M. (Eds), Handbook of Motivation and Cognition: Foundations of Social Behavior, Guilford, New York, NY, Vol. 2, pp. 408-448.

Swann, W.B., Jr and Buhrmester, M.D. (2012), "Self as functional fiction", Social Cognition, Vol. 30 No. 4, pp. 415-430.

Van Iddekinge, C.H., Ferris, G.R. and Heffner, T.S. (2009), "Test of a multistage model of distal and proximal antecedents of leader performance”, Personnel Psychology, Vol. 62 No. 3, pp. 463-495.

Wang, S. and Noe, R.A. (2010), "Knowledge sharing: a review and directions for future research", Human Resource Management Review, Vol. 20 No. 2, pp. 115-131.

Westhead, P. (1995), "Survival and employment growth contrasts between types of owner-managed high-technology firms", Entrepreneurship Theory and Practice, Vol. 20 No. 1, Vol. 20, pp. 5-27.

Wu, Y. (2015), "Organizational structure and product choice in knowledge-intensive firms", Management Science, Vol. 61 No. 8, pp. 1830-1848.

\section{Further reading}

Byrne, B.M. (1998), Structural Equation Modelling with LISREL, PRELIS and SIMPLIS: Basic Concepts, Applications, and Programming, Erlbaum, Mahwah, NJ.

Carmines, E.G. and Zeller, R.A. (1979), Reliability and Validity Assessment, Vol. 17, Sage Publications.

Delmas, M.A. and Montes-Sancho, M.J. (2011), "US state policies for renewable energy: context and effectiveness", Energy Policy, Vol. 39 No. 5, pp. 2273-2288. 
Delmas, M.A. and Toffel, M.W. (2008), "Organizational responses to environmental demands: opening the black box", Strategic Management Journal, Vol. 29 No. 10, pp. 1027-1055.

Downey, R.G. and King, C.V. (1998), "Missing data in likert ratings: a comparison of replacement methods", The Journal of General Psychology, Vol. 125 No. 2, pp. 175-191.

Hayes, A.F. (2009), "Beyond Baron and Kenny: statistical mediation analysis in the new millennium", Communication Monographs, Vol. 76 No. 4, pp. 408-420

Jarvenpaa, S.L. and Staples, D.S. (2000), "The use of collaborative electronic media for information sharing: an exploratory study of determinants", The Journal of Strategic Information Systems, Vol. 9 Nos 2/3, pp. 129-154.

Roth, P.L. and Switzer, F.S. (1995), "A Monte Carlo analysis of missing data techniques in a HRM setting", Journal of Management, Vol. 21 No. 5, pp. 1003-1023.

\section{Appendix. Scales}

Professional-role-identity adopted from McDearmon (2013)

- Professional duties in my field takes priority in my mind in some way;

- Carrying out professional duties in my field is an important part of my work;

- Actively learning and contributing in my professional field is an important part of my work; and

- Giving back more than what I have learned from my community is my duty.

Knowledge helping adopted from Mittal et al. (2018)

- I help team members learn how to do the work;

- I help team members who are lacking in requisite skills;

- I train the team members to develop their skills;

- I help team members further develop their skills;

- I assist team members in devising the solution to the problems at hand;

- I talk through problems at work, helping to come up with solution;

- I help team members when they are not sure what to do in the situation; and

- I advise team members when the situation is new for them.

NB: Items 1-4 are meant for 'professional development' dimension and items 5-8 for 'problem mitigation' dimension.

Knowledge sharing adopted from Huang et al. (2014)

- I share my experience or know-how from work with members in this team;

- I provide my know-where or know-whom at the request of other team members;

- I share my expertise from my education or training with other team members;

- I share my work reports and official documents with members in this team; and

- I provide my manuals, methodologies and models for members of this team.

NB: Items 1-3 are meant for tacit knowledge sharing dimension and Items 4-5 for explicit knowledge sharing dimension.

Knowledge-based effectiveness: team learning (Gray and Meister, 2004) and team leadership (Morgeson et al., 2010)

- Contribution in team learning is defined as the individual team member's contribution in the overall task and skill based learning of the team during formal and informal 
interactions in the team. Observable contributions could be enhancing team member's ability to replicate, adapt or innovate. Rate each of your team members on contribution in team learning on a 1-5 scale; 1 being highly ineffective and 5 being highly effective.

- Team Leadership is defined as the responsibility assumed by a team member, who is not the supervisor or formal team leader/manager, of satisfying team's needs in the service of enhancing team effectiveness. Observable behaviours could be acting as a informal mentor or coach for the team members Rate each of your team members on team leadership on a $1-5$ scale; 1 being highly ineffective and 5 being highly effective.

\title{
Knowledge, skills and abilities as dimensions taken from Faraj and Sproull (2000), Blader and Chen (2012) and Hofmann et al. (2009)
}

- Rate your proficiency level in the domain of your expertise;

- Your total work experience in the domain of your expertise;

- To what extent your skills sets are adequate in your field;

- Rate yourself on your current hierarchy-level in the organization, top being rated as highest and down being rated as lowest;

- Rate yourself on the access to organizational knowledge resources;

- Rate yourself on the access to knowledge in your field;

- Your level of relevant education in your field;

- Rate yourself on the formal trainings and certifications done by you in your field; and

- Rate yourself on the product/process innovation done by you in the past.

NB: Items 1-3 are meant for 'skill' dimension; items 4-6 for 'ability' dimension, and items 7-9 for 'knowledge' dimension.

Knowledge self-efficacy adapted from Kankanhalli et al. (2005)

- I have confidence in my ability to provide knowledge that others in my team consider valuable;

- I have the expertise needed to provide valuable knowledge for my team; and

- Most other employees in my team can provide more valuable knowledge than I can.

\begin{abstract}
About the authors
Sanjay Kumar Singh is an Associate Professor of Management at College of Business, Abu Dhabi University, Abu Dhabi, UAE. His research interests include Big Data analytics, diversity management, emotional intelligence, knowledge management, green innovation, sustainability, international HRM and SMEs. Sanjay Kumar Singh is the corresponding author and can be contacted at: sanjay.singh@adu.ac.ae

Shashank Mittal is affiliated with Rajagiri Business School in the field of OB and HRM. He received his Doctorate from Indian Institute of Management Raipur. He has over five years of work experience. He has presented papers in many international and national seminar and conferences and has published paper in reputed journals. His current research area is knowledge management.

Atri Sengupta is currently affiliated with the Indian Institute of Management Sambalpur (IIM Sambalpur) as an Assistant Professor in the field of OB and HRM. She has over 17 years' work experience. Prior to IIM Sambalpur, she was affiliated with Indian Institute of Management Raipur. She received PhD from Indian Institute of Technology Kharagpur. She has authored two books and several book chapters. She has also published articles in national and international journals of repute.
\end{abstract}


Rabindra Kumar Pradhan is an Associate Professor in the Department of Humanities and Social Sciences, Indian Institute of Technology Kharagpur, India. He is actively involved in research in various areas of industrial and organizational psychology, human resource development and management, organizational behaviour and positive psychology. He has more than 20 years of research and teaching experiences and has more than 100 publications in journals, conference proceedings, books, etc. He has edited 04 books and guided $09 \mathrm{PhD}$ scholars for doctoral degree. He has presented numerous papers in multiple forums of international and national conferences in India and foreign countries.

For instructions on how to order reprints of this article, please visit our website: www.emeraldgrouppublishing.com/licensing/reprints.htm

Or contact us for further details: permissions@emeraldinsight.com 